\title{
Differential Association of Vitamin D Deficiency With Albuminuria by Sex in the Korean General Population: A Cross-sectional Study of the Korea National Health and Nutrition Examination Survey 2011-2012
}

\author{
Yongwoo Jeon ${ }^{1,2}$, Jaeyong Shin ${ }^{1,2}$, Jong Hyun Jhee ${ }^{3}$, Youngdae Cho ${ }^{1,2}$, Eun-Cheol Park ${ }^{1,4}$ \\ ${ }^{1}$ Department of Preventive Medicine, Yonsei University College of Medicine, Seoul, Korea; ${ }^{2}$ Department of Public Health, Yonsei University Graduate \\ School, Seoul, Korea; ${ }^{3}$ Department of Nephrology, Yonsei University College of Medicine, Seoul, Korea; ${ }^{4}$ Institute of Health Services Research, Yonsei \\ University College of Medicine, Seoul, Korea
}

Objectives: Albuminuria has emerged as a biomarker for several medical conditions, and vitamin $\mathrm{D}$ has received attention due to its associations with various disorders. We evaluated the association between low serum vitamin $D$ levels and prevalent albuminuria by sex in the Korean general population.

Methods: We analyzed 9823 participants (4401 males, 5422 females) from the Korea National Health and Nutrition Examination Survey 2011-2012 (KNHANES V-2), and categorized them as having a normal range of vitamin D levels, vitamin D insufficiency, or vitamin D deficiency. A multivariable logistic regression model was used to compare the risk of albuminuria across these groups. Stratified analyses were conducted by smoking status, obesity, and renal function.

Results: Albuminuria was found in 325 of the 4401 male participants (7.4\%) and in 455 of the 5422 female participants (8.4\%). Among the males, vitamin D deficiency was associated with an odds ratio (OR) for albuminuria of 1.78 (95\% confidence interval [Cl], 1.07 to $2.97, p<0.05)$. However, such an association was not found in females. The association was stronger in male current smokers (OR, 3.54; $95 \% \mathrm{Cl}, 1.47$ to $8.50 ; p=0.005)$.

Conclusions: The findings of this study suggest that sex differences exist in the association between serum vitamin $D$ deficiency and albuminuria. Additionally, we observed that the association was stronger in current smokers than in the overall male population, but was not seen in non-smokers. Therefore, different approaches by sex and smoking status might be needed when considering using vitamin $\mathrm{D}$ as a biomarker for renal function.

Key words: Vitamin D deficiency, Albuminuria, Sex factors, Smoking, Korea

\section{INTRODUCTION}

Received: January 5, 2017 Accepted: January 23, 2018

Corresponding author: Eun-Cheol Park, MD, PhD Department of Preventive Medicine, Yonsei University College of Medicine, 50-1 Yonsei-ro, Seodaemun-gu, Seoul 03722, Korea E-mail: ecpark@yuhs.ac

This is an Open Access article distributed under the terms of the Creative Commons Attribution Non-Commercial License (http://creativecommons.org/licenses/by$\mathrm{nc} / 4.0 /$ ) which permits unrestricted non-commercial use, distribution, and reproduction in any medium, provided the original work is properly cited.
Albuminuria is not only a prognostic marker for renal disease, but also a significant predictor of cardiovascular disease and all-cause mortality $[1,2]$. Because of its broad range of implications, albuminuria itself has been targeted as a therapeutic goal to prevent the progression of certain medical conditions [1-3]. It was reported that $6.2 \%$ of the general population had albuminuria in Korea, while $29.9 \%$ of the subjects with micro- 
albuminuria had intact renal function [3]. Albuminuria is normally defined by levels of the urinary albumin/creatinine ratio (UACR) over $30 \mathrm{mg} / \mathrm{g}$. Albuminuria in individuals without kidney disease may occur due to systemic endothelial dysfunction in the kidney.

Vitamin D has recently received attention from medical researchers due to its associations with various non-osteoskeletal disorders [4-9]. Those medical conditions include hypertension, diabetes mellitus, obesity, cardiovascular disease, cancers, infections, and autoimmune diseases $[4,6,10,11]$. Serum 25-hydroxyvitamin D production from cutaneous sources has decreased since people started engaging more in indoor jobs. Despite its important roles in the human body, only $13.2 \%$ of males and $6.7 \%$ of females in the Korean adult population were reported to have sufficient levels of vitamin $D$ [12]. Another study reported that $49.9 \%$ of males and $67.4 \%$ of females in the Korean general population had insufficient or deficient levels of serum vitamin $D$, which is a much higher rate than has been observed in Western countries. Moreover, vitamin D deficiency was more prevalent in young adults in Korea [13].

Over the years, many studies have demonstrated a significant link between serum vitamin D deficiency and albuminuria [10, $14,15]$. However, it is still controversial whether vitamin D replacement therapy could delay the progress of chronic kidney disease or reduce the incidence of albuminuria [16]. Some studies in Korea showed that vitamin D deficiency was associated with the estimated glomerular filtration rate (eGFR) in healthy adults, while others showed that severe vitamin $D$ deficiency could result in increased UACR levels among individuals with normo-albuminuria $[17,18]$.

However, to our knowledge, the association between vitamin $D$ deficiency and albuminuria in the general population in Korea has not yet been investigated. Moreover, since sex has strong effects on the prevalence of albuminuria and on vitamin D metabolism $[2,19]$, it is necessary to explore whether sex has confounding effects or interaction effects on the association between these 2 variables. The aim of our study was to assess the association between low serum vitamin D levels and albuminuria separately by sex in the Korean general population.

\section{METHODS}

\section{Data Source and Study Population}

The Korea National Health and Nutrition Examination Survey (KNHANES) is a nationwide population-based cross-sec- tional survey. Detailed information about the survey has been presented elsewhere [20]. As data on urinary albumin levels were first collected in 2011, we used data from the KNHANES V-2, which contains samples from 2011-2012. A standardized questionnaire was given to all participants to collect information on socio-demographic variables, family history, medical history, and other health-related variables. Among 12729 members of the adult population, participants who had missing data on key variables such as serum vitamin $D(n=1264)$, the UACR $(n=840)$, and other parameters were excluded, and 10164 participants remained. We additionally excluded 79 pregnant females, 213 cancer patients, and 40 chronic renal failure patients, because those health states could strongly affect the association [15]. We also excluded 9 individuals with no diagnosis of chronic renal failure who nonetheless had a UACR over $3000 \mathrm{mg} / \mathrm{g}$, indicating nephrotic-range albuminuria, which is known to affect vitamin D metabolism [15]. A final total of 9823 subjects were analyzed in this study. Informed consent for participation in the KNHANES V-2 was granted by all subjects, so we did not need to obtain separate consent for this study.

\section{Definition of Albuminuria and Vitamin D Deficiency}

We used the UACR $(\mathrm{mg} / \mathrm{g})$ to determine whether a participant had albuminuria. Albuminuria was considered to be present in individuals with a UACR $\geq 30 \mathrm{mg} / \mathrm{g}$ and absent in others [21]. Based on previous studies, vitamin D deficiency was defined as serum $25(\mathrm{OH}) \mathrm{D}$ levels less than $12 \mathrm{ng} / \mathrm{mL}$, vitamin $D$ insufficiency as $12-20 \mathrm{ng} / \mathrm{mL}$, and the normal range as over 20 $\mathrm{ng} / \mathrm{mL}[9,15,22]$.

\section{Definition of Covariates}

Participants were classified according to body mass index (BMI) as low body weight $\left(<18.5 \mathrm{~kg} / \mathrm{m}^{2}\right)$, normal $(18.5-25.0$ $\left.\mathrm{kg} / \mathrm{m}^{2}\right)$, or obese $\left(\geq 25.0 \mathrm{~kg} / \mathrm{m}^{2}\right)$. The place of residence of participants was categorized based on their address; those who had a final address unit of 'dong' were classified as residing in an urban area, while those who had a final address unit of 'eup' or 'myeon' were classified as residing in a rural area. The latitude of participants' places of residence varied from 33.36 to 37.57 degrees north, so we additionally categorized them by geometric tertiles as south, middle, or north. We defined whitecollar workers as those who worked as managers, professionals, office workers, and indoor service providers; blue-collar 
workers as those who worked in agriculture, forestry, fishery, machinery, and as general laborers; and others as those who fell into other occupational categories, including homemakers and students. The eGFR was calculated from age, sex, and serum creatinine concentration using the Chronic Kidney Disease Epidemiology Collaboration equation: eGFR $\left(\mathrm{mL} / \mathrm{min} / 1.73 \mathrm{~m}^{2}\right)$ $=141 \times \min (\mathrm{SCr} / \kappa, 1)^{a} \times \max (\mathrm{SCr} / \kappa, 1)^{-1.209} \times 0.993^{\mathrm{Age}} \times 1.018$ if female, where $\mathrm{SCr}$ is serum creatinine, $\kappa$ is 0.7 for females and 0.9 for males, $a$ is -0.329 for females and -0.411 for males, min indicates the minimum value of $\mathrm{S} C \mathrm{r} / \mathrm{\kappa}$ or 1 , and max indicates the maximum value of $\mathrm{SCr} / \kappa$ or 1 [23]. A decreased eGFR was defined as an eGFR $<60 \mathrm{~mL} / \mathrm{min} / 1.73 \mathrm{~m}^{2}$. Those who stated on the questionnaire that they smoked at the present time were categorized as current smokers and the others as nonsmokers. Current drinkers were defined in this study as those who drank at least once a month. We defined regular walking as walking at least 30 minutes a day on 5 days a week on average. Participants were asked about the average amount of

Table 1. General characteristics by vitamin D status ${ }^{1}$ in each sex

\begin{tabular}{|c|c|c|c|c|c|c|c|c|}
\hline \multirow[b]{2}{*}{ Characteristics } & \multicolumn{4}{|c|}{ Male } & \multicolumn{4}{|c|}{ Female } \\
\hline & $\begin{array}{l}\text { Normal } \\
(n=1511)\end{array}$ & $\begin{array}{c}\text { Vitamin D } \\
\text { insufficiency } \\
(n=2352)\end{array}$ & $\begin{array}{c}\text { Vitamin D } \\
\text { deficiency } \\
(n=538)\end{array}$ & $p$-value & $\begin{array}{c}\text { Normal } \\
(\mathrm{n}=1289)\end{array}$ & $\begin{array}{c}\text { Vitamin D } \\
\text { insufficiency } \\
(\mathrm{n}=\mathbf{2 9 9 3 )}\end{array}$ & $\begin{array}{c}\text { Vitamin D } \\
\text { deficiency } \\
(\mathrm{n}=1140)\end{array}$ & $p$-value \\
\hline Age (y) & $55.2 \pm 14.8$ & $49.3 \pm 16.0$ & $46.6 \pm 16.7$ & $<0.001$ & $58.6 \pm 14.6$ & $50.9 \pm 15.6$ & $48.1 \pm 16.6$ & $<0.001$ \\
\hline Body mass index $\left(\mathrm{kg} / \mathrm{m}^{2}\right)$ & $23.9 \pm 2.9$ & $24.2 \pm 3.2$ & $23.9 \pm 3.4$ & $<0.001$ & $23.8 \pm 3.3$ & $23.7 \pm 3.6$ & $23.1 \pm 3.6$ & $<0.001$ \\
\hline Rural area & $474(31.4)$ & $392(16.7)$ & 64 (11.9) & $<0.001$ & $384(29.8)$ & $578(19.3)$ & $157(13.8)$ & $<0.001$ \\
\hline Latitude & & & & $<0.001$ & & & & $<0.001$ \\
\hline Northern & $590(39.1)$ & $1269(54.0)$ & $353(65.6)$ & & $524(40.7)$ & $1484(49.6)$ & $704(61.8)$ & \\
\hline Middle & $757(50.1)$ & $982(41.8)$ & $165(30.7)$ & & $629(48.8)$ & $1327(44.3)$ & 397 (34.8) & \\
\hline Southern & $164(10.9)$ & $101(4.3)$ & $20(3.7)$ & & $136(10.6)$ & $182(6.1)$ & $39(3.4)$ & \\
\hline Occupation & & & & $<0.001$ & & & & $<0.001$ \\
\hline White-collar & $447(29.6)$ & $992(42.2)$ & $229(42.6)$ & & $254(19.7)$ & $887(29.6)$ & $384(33.7)$ & \\
\hline Blue-collar & $711(47.1)$ & $816(34.7)$ & $144(26.8)$ & & $357(27.7)$ & $559(18.7)$ & $147(12.9)$ & \\
\hline Other (students, homemakers, etc.) & $353(23.4)$ & $544(23.1)$ & $165(30.7)$ & & $678(52.6)$ & $1547(51.7)$ & $609(53.4)$ & \\
\hline $\mathrm{eGFR}\left(\mathrm{mL} / \mathrm{min} / 1.73 \mathrm{~m}^{2}\right)^{2}$ & $86.9 \pm 15.0$ & $91.3 \pm 16.0$ & $94.5 \pm 17.5$ & $<0.001$ & $88.6 \pm 16.5$ & $95.7 \pm 17.0$ & $99.2 \pm 17.8$ & $<0.001$ \\
\hline Albuminuria ${ }^{3}$ & $122(8.1)$ & $158(6.7)$ & $45(8.4)$ & & $130(10.1)$ & $231(7.7)$ & $94(8.3)$ & \\
\hline Systolic blood pressure (mmHg) & $122.7 \pm 16.4$ & $121.3 \pm 15.0$ & $120.5 \pm 15.4$ & 0.004 & $121.7 \pm 18.4$ & $117.6 \pm 17.7$ & $117.1 \pm 18.3$ & $<0.001$ \\
\hline Diastolic blood pressure (mmHg) & $77.9 \pm 10.7$ & $78.7 \pm 10.4$ & $78.5 \pm 11.2$ & 0.09 & $74.4 \pm 9.5$ & $73.9 \pm 9.7$ & $74.0 \pm 9.8$ & 0.19 \\
\hline Total cholesterol (mg/dL) & $187.9 \pm 34.1$ & $189.1 \pm 35.9$ & $185.5 \pm 37.0$ & 0.10 & $196.3 \pm 36.3$ & $193.4 \pm 37.4$ & $190.7 \pm 36.9$ & 0.001 \\
\hline Triglycerides (mg/dL) & $141.0 \pm 101.1$ & $157.3 \pm 135.9$ & $164.2 \pm 115.4$ & $<0.001$ & $119.7 \pm 68.5$ & $117.7 \pm 87.3$ & $120.6 \pm 99.1$ & 0.55 \\
\hline \multicolumn{9}{|l|}{ Current medication } \\
\hline Hypertension & $352(23.3)$ & $461(19.6)$ & $92(17.1)$ & 0.002 & 403 (31.3) & $624(20.9)$ & $221(19.4)$ & $<0.001$ \\
\hline Diabetes mellitus & $149(9.9)$ & $178(7.6)$ & $48(8.9)$ & 0.04 & $118(9.2)$ & $182(6.1)$ & $79(6.9)$ & 0.001 \\
\hline Dyslipidemia & $98(6.5)$ & $132(5.6)$ & $28(5.2)$ & 0.42 & $137(10.6)$ & $211(7.1)$ & $82(7.2)$ & $<0.001$ \\
\hline Current smoker ${ }^{4}$ & $562(37.2)$ & $952(40.5)$ & $265(49.3)$ & $<0.001$ & $44(3.4)$ & $165(5.5)$ & $72(6.3)$ & 0.003 \\
\hline Current drinker $^{5}$ & $1081(71.5)$ & $1759(74.8)$ & $385(71.6)$ & 0.05 & $391(30.3)$ & $1155(38.6)$ & $384(33.7)$ & $<0.001$ \\
\hline Regular walking ${ }^{6}$ & 656 (43.4) & 907 (38.6) & $221(41.1)$ & 0.01 & 448 (34.8) & 1058 (35.4) & 363 (31.8) & 0.10 \\
\hline Sun exposure & $392(25.9)$ & $314(13.4)$ & $62(11.5)$ & $<0.001$ & $206(16.0)$ & 239 (8.0) & $50(4.4)$ & $<0.001$ \\
\hline
\end{tabular}

Values are presented as mean \pm standard deviation or number (\%).

eGFR, estimated glomerular filtration rate; CKD-EPI, Chronic Kidney Disease Epidemiology Collaboration.

'Vitamin D insufficiency was defined as serum vitamin D levels of $12-20 \mathrm{ng} / \mathrm{dL}$; Vitamin D deficiency was defined as serum vitamin D levels of $\leq 12 \mathrm{ng} / \mathrm{dL}$.

${ }^{2}$ Calculated using the CKD-EPI equation. eGFR $\left(\mathrm{mL} / \mathrm{min} / 1.73 \mathrm{~m}^{2}\right)=141 \times \mathrm{min}(\mathrm{SCr} / \kappa, 1)^{\alpha} \times \max (\mathrm{SCr} / \kappa, 1)^{-1.209} \times 0.993^{\mathrm{Age}} \times 1.018$ if female, where SCr is serum creatinine, $\kappa$ is 0.7 for females and 0.9 for males, $\alpha$ is -0.329 for females and -0.411 for males, min indicates the minimum value of SCr/ $\kappa$ or 1 , and max indicates the maximum value of $\mathrm{SCr} / \kappa$ or 1 .

${ }^{3}$ Urinary albumin/creatinine ratio $\geq 30 \mathrm{mg} / \mathrm{g}$.

${ }^{4}$ Indicates those who reported smoking at the present time.

${ }^{5}$ Indicates those who reported drinking at least once a month at the present time.

${ }^{6}$ Indicates those who walked continuously for at least $30 \mathrm{~min} / \mathrm{d}, 5 \mathrm{~d} / \mathrm{wk}$.

${ }^{7}$ Indicates the proportion of those who were exposed to sunlight for more than $5 \mathrm{hr} / \mathrm{d}$. 
time that they were exposed to direct sunlight each day. Sun exposure was defined in this study as being exposed to direct sunlight for more than 5 hours a day on average.

\section{Statistical Analysis}

Differences in general characteristics by vitamin D status were evaluated using the chi-square test and one-way analysis of variance in each sex. Logistic regression analyses were employed to investigate the associations between vitamin D deficiency and the prevalence of albuminuria. We analyzed the association in the total population and also separately by sex. We adjusted for age, BMI, rural area, latitude, and occupation in model 1 , and sex was also adjusted for in the estimation for the total population. Medical factors such as the eGFR, systolic blood pressure, diastolic blood pressure, total cholesterol, triglyceride levels, and current medication for hypertension, diabetes mellitus, and dyslipidemia were added to model 2 . In the final model, lifestyle factors such as smoking status, drinking status, regular walking, and sun exposure were additionally adjusted for. We analyzed the association stratified by smoking status, decreased eGFR, and obesity, since those variables showed significant differences in the univariate analysis by vitamin $\mathrm{D}$ status and are known to be possible effect modifiers.
To test the robustness of our study, we repeated the analysis with a redefinition of vitamin $D$ deficiency as less than $10 \mathrm{ng} /$ $\mathrm{mL}$ and vitamin $D$ insufficiency as $10-20 \mathrm{ng} / \mathrm{mL}$ as a sensitivity analysis. All statistical analyses were performed using SAS version 9.4 (SAS Institute Inc., Cary, NC, USA).

\section{RESULTS}

The general characteristics of the 9823 total participants are shown in Table 1 separately by sex (4401 males and 5422 females). Among the total population, 5345 individuals (54.4\%) were classified as having vitamin D insufficiency, and 1678 (17.1\%) had vitamin D deficiency (males: 538, 12.2\%; females: $1140,21.0 \%)$. The mean eGFR was higher in the vitamin D deficiency group than in the normal-range group in both males and females $\left(94.5 \pm 17.5 \mathrm{vs.} 86.9 \pm 15.0 \mathrm{~mL} / \mathrm{min} / 1.73 \mathrm{~m}^{2}\right.$ in males; $99.2 \pm 17.8$ vs. $88.6 \pm 16.5 \mathrm{~mL} / \mathrm{min} / 1.73 \mathrm{~m}^{2}$ in female). Among male participants, albuminuria was likewise more common in the vitamin $D$ deficiency group than in the normal-range group (8.4 vs. $8.1 \%$ ). However, among the female participants, it was more common in the normal-range group ( 8.3 vs. $10.1 \%)$. Systolic blood pressure was the lowest in the vitamin $\mathrm{D}$ deficiency group in both sexes. The total cholesterol level significantly

Table 2. Risks of albuminuria according to vitamin D status ${ }^{1}$ in each sex

\begin{tabular}{|c|c|c|c|c|c|c|c|c|c|c|}
\hline \multirow[b]{2}{*}{ Vitamin D status } & \multirow{2}{*}{$\begin{array}{c}\text { Total } \\
\text { (n) }\end{array}$} & \multirow{2}{*}{$\begin{array}{l}\text { Albu- } \\
\text { minuria } \\
\text { (n) }\end{array}$} & \multicolumn{2}{|c|}{ Unadjusted model } & \multicolumn{2}{|c|}{ Adjusted model $1^{2}$} & \multicolumn{2}{|c|}{ Adjusted model $2^{3}$} & \multicolumn{2}{|c|}{ Adjusted model $3^{4}$} \\
\hline & & & $\begin{array}{c}\text { OR } \\
(95 \% \text { CI) }\end{array}$ & $\begin{array}{c}p- \\
\text { value }\end{array}$ & $\begin{array}{c}\text { OR } \\
(95 \% \text { CI) }\end{array}$ & $\begin{array}{c}p- \\
\text { value }\end{array}$ & $\begin{array}{c}\text { OR } \\
(95 \% \text { CI })\end{array}$ & $\begin{array}{c}p- \\
\text { value }\end{array}$ & $\begin{array}{c}\text { OR } \\
(95 \% \text { Cl })\end{array}$ & $\begin{array}{c}p- \\
\text { value }\end{array}$ \\
\hline Normal & 2800 & 252 & 1.00 (reference) & & 1.00 (reference) & & 1.00 (reference) & & 1.00 (reference) & \\
\hline Vitamin D insufficiency & 5345 & 389 & $0.74(0.60,0.92)$ & 0.006 & $0.99(0.79,1.24)$ & 0.91 & $1.01(0.80,1.28)$ & 0.94 & $1.01(0.80,1.27)$ & 0.96 \\
\hline Vitamin D deficiency & 1678 & 139 & $0.96(0.72,1.28)$ & 0.79 & $1.49(1.09,2.04)$ & 0.01 & $1.47(1.06,2.04)$ & 0.02 & $1.46(1.06,2.02)$ & 0.02 \\
\hline Normal & 1511 & 122 & 1.00 (reference) & & 1.00 (reference) & & 1.00 (reference) & & 1.00 (reference) & \\
\hline Vitamin D insufficiency & 2352 & 158 & $0.78(0.58,1.06)$ & 0.11 & $1.10(0.79,1.54)$ & 0.57 & $1.12(0.80,1.58)$ & 0.50 & $1.11(0.79,1.55)$ & 0.55 \\
\hline Vitamin D deficiency & 538 & 45 & $1.06(0.67,1.66)$ & 0.81 & $1.87(1.13,3.11)$ & 0.01 & $1.82(1.10,3.02)$ & 0.02 & $1.78(1.07,2.97)$ & 0.03 \\
\hline \multicolumn{11}{|l|}{ Female } \\
\hline Normal & 1289 & 130 & 1.00 (reference) & & 1.00 (reference) & & 1.00 (reference) & & 1.00 (reference) & \\
\hline
\end{tabular}

$\mathrm{OR}$, odds ratio; $\mathrm{Cl}$, confidence interval; eGFR, estimated glomerular filtration rate.

${ }^{1}$ Vitamin $D$ insufficiency was defined as serum vitamin D levels of $12-20 \mathrm{ng} / \mathrm{dL}$; Vitamin D deficiency was defined as serum vitamin D levels of $\leq 12 \mathrm{ng} / \mathrm{dL}$.

${ }^{2}$ Adjusted for age, body mass index, rural area, latitude, and occupation + sex (for the estimate in the total population).

${ }^{3}$ Adjusted for age, body mass index, rural area, latitude, occupation, eGFR, systolic blood pressure, diastolic blood pressure, total cholesterol, triglycerides, and medication (hypertension, diabetes mellitus, dyslipidemia) + sex (for the estimate in the total population).

${ }^{4}$ Adjusted for age, body mass index, rural area, latitude, occupation, eGFR, systolic blood pressure, diastolic blood pressure, total cholesterol, triglycerides, and medication (hypertension, diabetes mellitus, dyslipidemia), smoking status, drinking status, regular walking, and sun exposure + sex (for the estimate in the total population). 
Table 3. Risks of albuminuria according to vitamin D status' by smoking status

\begin{tabular}{|c|c|c|c|c|c|c|c|c|}
\hline \multirow[b]{2}{*}{ Vitamin D status } & \multicolumn{4}{|c|}{ Non-smokers ${ }^{2}$} & \multicolumn{4}{|c|}{ Current smokers ${ }^{3}$} \\
\hline & $\begin{array}{c}\text { Total } \\
\text { (n) }\end{array}$ & $\begin{array}{l}\text { Albuminuria } \\
\text { (n) }\end{array}$ & $\begin{array}{c}\text { OR } \\
(95 \% \mathrm{CI})\end{array}$ & $p$-value & $\begin{array}{c}\text { Total } \\
\text { (n) }\end{array}$ & $\begin{array}{l}\text { Albuminuria } \\
\text { (n) }\end{array}$ & $\begin{array}{c}\text { OR } \\
(95 \% \mathrm{CI})\end{array}$ & $p$-value \\
\hline \multicolumn{9}{|l|}{ Total } \\
\hline Normal & 2194 & 210 & 1.00 (reference) & & 606 & 42 & 1.00 (reference) & \\
\hline Vitamin D insufficiency & 4228 & 314 & $0.86(0.66,1.12)$ & 0.26 & 1117 & 75 & $1.75(0.93,3.27)$ & 0.08 \\
\hline Vitamin D deficiency & 1341 & 114 & $1.18(0.82,1.69)$ & 0.38 & 337 & 25 & $3.19(1.42,7.19)$ & 0.005 \\
\hline \multicolumn{9}{|l|}{ Male } \\
\hline Normal & 949 & 83 & 1.00 (reference) & & 552 & 39 & 1.00 (reference) & \\
\hline Vitamin D insufficiency & 1400 & 98 & $0.86(0.58,1.26)$ & 0.43 & 952 & 60 & $1.75(0.89,3.45)$ & 0.10 \\
\hline Vitamin D deficiency & 273 & 25 & $1.10(0.60,2.00)$ & 0.77 & 265 & 20 & $3.54(1.47,8.50)$ & 0.005 \\
\hline \multicolumn{9}{|l|}{ Female } \\
\hline Normal & 1245 & 127 & 1.00 (reference) & & 44 & 3 & 1.00 (reference) & \\
\hline Vitamin D insufficiency & 2828 & 216 & $0.86(0.62,1.21)$ & 0.39 & 165 & 15 & $3.84(0.90,16.38)$ & 0.07 \\
\hline Vitamin D deficiency & 1068 & 89 & $1.15(0.75,1.75)$ & 0.52 & 72 & 5 & $4.47(0.88,22.64)$ & 0.07 \\
\hline
\end{tabular}

All analyses herein presented were adjusted for age, body mass index, rural area, latitude, occupation, eGFR, systolic blood pressure, diastolic blood pressure, total cholesterol, triglycerides, medication (hypertension, diabetes mellitus, dyslipidemia), drinking status, regular walking, and sun exposure + sex (for the estimate in the total population).

$\mathrm{OR}$, odds ratio; $\mathrm{Cl}$, confidence interval; eGFR, estimated glomerular filtration rate.

'Vitamin D insufficiency was defined as serum vitamin D levels of $12-20 \mathrm{ng} / \mathrm{dL}$; Vitamin D deficiency was defined as serum vitamin D levels of $\leq 12 \mathrm{ng} / \mathrm{dL}$.

Indicates those who did not smoke at the present time.

${ }^{3}$ Indicates those who smoked at the present time.

decreased as vitamin $D$ levels decreased in the female population, but not in the male population. In contrast, triglyceride levels increased as vitamin D levels decreased in males, but not in females. The proportion of current smokers was higher in the vitamin $D$ deficiency group than in other vitamin $D$ status groups in both males and females, whereas the proportion of those who were exposed to direct sunlight for more than 5 hours a day was higher in the normal vitamin $D$ range group in both sexes.

Among the total population, 780 individuals (7.9\%) (males: $325,7.4 \%$; females: $455,8.4 \%$ ) had albuminuria. Table 2 shows the risks of albuminuria according to vitamin D status. In the fully adjusted model, vitamin $D$ deficiency conferred an odds ratio (OR) for albuminuria of 1.46 (95\% confidence interval [Cl], 1.06 to $2.02 ; p<0.05)$. In the male population, individuals with vitamin $D$ deficiency did not show a significantly higher risk of albuminuria in the unadjusted model. However, when possible confounders were adjusted for, they showed a higher risk of albuminuria than the reference group (those with vitamin $\mathrm{D}$ levels in the normal range), with an OR of $1.78(95 \% \mathrm{Cl}, 1.07$ to $2.97 ; p<0.05$ ) in the fully adjusted model. Those associations were not observed in the female population. In the sensitivity analysis, the association in males remained marginally significant (Table S1).
When stratified by smoking status (Table 3 ), the association was only present in current smokers $(\mathrm{OR}, 3.19 ; 95 \% \mathrm{Cl}, 1.42$ to 7.19 in the total population and $\mathrm{OR}, 3.54 ; 95 \% \mathrm{Cl}, 1.47$ to 8.50 in the male population). In Tables S2 and S3, the results of stratification by eGFR and obesity are shown. An association between vitamin $D$ deficiency and albuminuria was also observed in individuals with normal renal function (normal eGFR), but it disappeared in those with a decreased eGFR. When stratified by obesity, the normal-weight population showed a similar association in the total population and among male participants.

\section{DISCUSSION}

The main finding of this study is that vitamin D deficiency had a significant association with prevalent albuminuria in Korea, especially among males. Additionally, the association between vitamin D deficiency and albuminuria disappeared in non-smokers.

Some previous studies demonstrated an association of vitamin D deficiency with prevalent albuminuria $[10,14,15,17,18]$. Furthermore, some experimental studies have been conducted to investigate whether supplementation of vitamin D could improve albuminuria [24-26]. As a possible mechanism, it was 
suggested that albuminuria could be caused by several conditions - such as renin-angiotensin-aldosterone system activation, increased blood pressure, and impaired glucose metabolism — and that those conditions can result from podocyte loss and glomerulosclerosis, which could be caused by vitamin $D$ deficiency $[15,24,27,28]$. Conversely, albuminuria could cause vitamin $\mathrm{D}$ deficiency. The megalin and cubilin receptors actively reabsorb vitamin $D$ in the proximal tubule of the kidney. It is possible that additional filtered albumin could interfere with the reabsorption of vitamin $D$, resulting in vitamin $D$ deficiency [29].

Unlike other previous studies, we observed that sex modified the association between vitamin D deficiency and albuminuria. The interaction of sex on the association was observed even in subgroup analyses stratified by smoking status, eGFR, and obesity. Further studies may be required to explain the precise mechanism, but the following considerations could be possible explanations.

First, the different proportions of sex hormones by sex might be a reason for this trend. Some studies have proposed that estrogen protects females from the progression of renal function decline [30,31]. In contrast, androgens have been observed to cause males to experience a rapid decline of renal function compared to females [32]. It was reported that androgens activated the renin-angiotensin system, which could cause endothelial injury, and that testosterone could cause salt and water retention, possibly contributing to vascular injuries [33]. Several previous studies have suggested that vitamin D responsiveness also differs by the proportions of sexual hormones $[19,34]$. Not only the proportions, but androgens themselves, were suggested to have a significant association with vitamin D metabolism [35]. Second, anatomical differences by sex, such as the distribution of adiposity or responsiveness of the vasculature, could affect the mechanism through which vitamin D and albuminuria are associated. The higher proportion of adipose tissue in female versus male bodies was suggested to be a factor contributing to lower vitamin D concentrations [36]. The prevalence of vitamin $D$ deficiency was reported to be higher in females than in males [7], and almost double in the Korean population [13], as was found in our study (12.2 vs. $21.0 \%$ in males and females, respectively). In contrast, albuminuria has been reported to be more prevalent in males than in females [37]. This could be because the renal vasculature in males is more sensitive in some ways than the renal vasculature in females [30]. Similarly, the response of renal vessels to deficient levels of vitamin D could differ by sex.

The unique results of our study could also be attributable to ethnic and racial differences. Most previous studies were conducted in Caucasian populations, and UACR levels are affected by ethnicity and culturally-associated lifestyle factors (e.g., the more frequent ingestion of animal protein in Western cultures). The prevalence of albuminuria (7.9\%) in this study was lower than was reported in a previous study in the US (11.6\%) [15], and the occurrence of nephropathy is known to be affected by race [37]. Vitamin D metabolism also could differ by race and culture [21]. Some observational studies showed that vitamin $D$ deficiency was more prevalent in the Korean population than in the Caucasian population (17.1\% in our study, $3.7 \%$ in another study from the US) $[13,15]$. This could be due to differences in skin pigmentation or cultural practices, such as vitamin D supplementation, sunscreen application, and the use of sunglasses [13].

Smoking status also showed an effect modification in our subgroup analysis. If a male participant was a current smoker, the association between vitamin $D$ deficiency and albuminuria was much stronger, whereas the association disappeared in non-smokers. Even in the female population, the prevalence of albuminuria was much higher among smokers. Trials have investigated whether vitamin D supplementation could prevent albuminuria progression $[25,26]$, but we would instead suggest based on our observations that smoking cessation might work better.

Some limitations and strengths of our study should be considered. First, since this was a cross-sectional study, it was impossible to infer causal or temporal relationships. Second, some of the participants might have been taking antihypertensive medications, which could affect albuminuria. However, we did not consider the effects of the subtype of antihypertensive agents (e.g., angiotensin-converting enzyme inhibitors). Third, there could have been additional possible confounders involving behavioral factors that affect vitamin D deficiency, such as dietary habits, sunscreen use, or clothing, which we could not analyze [12]. Our study also had important strengths. This study analyzed KNHANES data, which represent the general population of Korea with a large sample size. Moreover, unlike other studies, we analyzed the association separately by sex and investigated the association in an Asian population.

We conclude that sex differences exist in the association between serum vitamin $D$ deficiency and increased urinary albumin excretion. Low levels of vitamin $D$ had a significant corre- 
lation with prevalent albuminuria in the Korean male population, but not in females. Additionally, we also observed that the association was stronger in current smokers than in the total population, but was not seen in non-smokers. These findings suggest that different approaches by sex and smoking status might be needed when considering the use of vitamin $\mathrm{D}$ as a biomarker for renal function.

\section{ACKNOWLEDGEMENTS}

This work was supported by the Korea Centers for Disease Control and Prevention (no. 2012 E3301900\#). The funders had no role in the study design, data collection and analysis, decision to publish, or preparation of the manuscript.

\section{CONFLICT OF INTEREST}

The authors have no conflicts of interest associated with the material presented in this paper.

\section{SUPPLEMENTARY MATERIALS}

Supplementary Material 1: Table $\mathrm{S} 1$ is available at https:// www.jpmph.org/.

Supplementary Material 2: Table S2 is available at https:// www.jpmph.org/.

Supplementary Material 3: Table S3 is available at https:// www.jpmph.org/.

\section{ORCID}

Yongwoo Jeon https://orcid.org/0000-0002-0659-4159

Youngdae Cho http://orcid.org/0000-0003-1574-0012

Eun-Cheol Park http://orcid.org/0000-0002-2306-5398

\section{REFERENCES}

1. Hillege HL, Fidler V, Diercks GF, van Gilst WH, de Zeeuw D, van Veldhuisen $D J$, et al. Urinary albumin excretion predicts cardiovascular and noncardiovascular mortality in general population. Circulation 2002;106(14):1777-1782.

2. Jang M, Oh S, Noh HM, Chun S, Oh HY, Park KH, et al. Differences in factors associated with albuminuria according to gender and comorbidities of hypertension and diabetes. Korean J Fam Med 2015;36(6):316-322.
3. Won JC, Lee YJ, Kim JM, Han SY, Noh JH, Ko KS, et al. Prevalence of and factors associated with albuminuria in the Korean adult population: the 2011 Korea National Health and Nutrition Examination Survey. PLoS One 2013;8(12):e83273.

4. Giovannucci E, Liu Y, Hollis BW, Rimm EB. 25-Hydroxyvitamin $D$ and risk of myocardial infarction in men: a prospective study. Arch Intern Med 2008;168(11):1174-1180.

5. Nam GE, Kim DH, Cho KH, Park YG, Han KD, Kim SM, et al. 25-Hydroxyvitamin $\mathrm{D}$ insufficiency is associated with cardiometabolic risk in Korean adolescents: the 2008-2009 Korea National Health and Nutrition Examination Survey (KNHANES). Public Health Nutr 2014;17(1):186-194.

6. Ginde AA, Mansbach JM, Camargo CA Jr. Association between serum 25-hydroxyvitamin $D$ level and upper respiratory tract infection in the Third National Health and Nutrition Examination Survey. Arch Intern Med 2009;169(4):384-390.

7. McCullough ML, Weinstein SJ, Freedman DM, Helzlsouer K, Flanders WD, Koenig K, et al. Correlates of circulating 25-hydroxyvitamin D: cohort consortium vitamin $\mathrm{D}$ pooling project of rarer cancers. Am J Epidemiol 2010;172(1):21-35.

8. Kang JW, Choi HS, Kim K, Choi JY. Dietary vitamin intake correlates with hearing thresholds in the older population: the Korean National Health and Nutrition Examination Survey. Am J Clin Nutr 2014;99(6):1407-1413.

9. Yoo EH, Cho HJ. Prevalence of 25-hydroxyvitamin D deficiency in Korean patients with anemia. J Clin Lab Anal 2015;29(2):129134.

10. Isakova T, Gutiérrez OM, Patel NM, Andress DL, Wolf M, Levin A. Vitamin $D$ deficiency, inflammation, and albuminuria in chronic kidney disease: complex interactions. J Ren Nutr 2011;21(4): 295-302.

11. Mattila C, Knekt P, Männistö S, Rissanen H, Laaksonen MA, Montonen J, et al. Serum 25-hydroxyvitamin D concentration and subsequent risk of type 2 diabetes. Diabetes Care 2007;30(10): 2569-2570.

12. Choi HS, Oh HJ, Choi H, Choi WH, Kim JG, Kim KM, et al. Vitamin $D$ insufficiency in Korea--a greater threat to younger generation: the Korea National Health and Nutrition Examination Survey (KNHANES) 2008. J Clin Endocrinol Metab 2011;96(3): 643-651.

13. Choi EY. 25(OH)D status and demographic and lifestyle determinants of 25(OH)D among Korean adults. Asia Pac J Clin Nutr 2012;21(4):526-535.

14. Sonneveld R, Hoenderop JG, Stavenuiter AW, Ferrantelli E, Baltissen MP, Dijkman HB, et al. 1,25-Vitamin D3 deficiency induc- 
es albuminuria. Am J Pathol 2016;186(4):794-804.

15. de Boer IH, loannou GN, Kestenbaum B, Brunzell JD, Weiss NS. 25-Hydroxyvitamin D levels and albuminuria in the Third National Health and Nutrition Examination Survey (NHANES III). Am J Kidney Dis 2007;50(1):69-77.

16. Kim SM, Choi HJ, Lee JP, Kim DK, Oh YK, Kim YS, et al. Prevalence of vitamin $D$ deficiency and effects of supplementation with cholecalciferol in patients with chronic kidney disease. J Ren Nutr 2014;24(1):20-25.

17. Oh YJ, Park RW, Yoon D, Kim M, Han SS, Jang HR, et al. Non-linear association of serum 25-hydroxyvitamin D with urinary albumin excretion rate in normoalbuminuric subjects. BMC Nephrol 2014;15:97.

18. Tak YJ, Lee JG, Song SH, Kim YJ, Lee S, Jung DW, et al. The relationship between the level of serum 25 -hydroxyvitamin $D$ and renal function in patients without chronic kidney disease: a cross-sectional study. J Ren Nutr 2015;25(2):88-96.

19. Eikelenboom MJ, Killestein J, Kragt JJ, Uitdehaag BM, Polman $\mathrm{CH}$. Gender differences in multiple sclerosis: cytokines and vitamin D. J Neurol Sci 2009;286(1-2):40-42.

20. Kim TH, Lee MJ, Yoo KB, Han E, Choi JW. Association of demographic and socioeconomic factors with risk factors for chronic kidney disease. J Prev Med Public Health 2015;48(3):170177.

21. Choi HS, Sung KC, Lee KB. The prevalence and risk factors of microalbuminuria in normoglycemic, normotensive adults. Clin Nephrol 2006;65(4):256-261.

22. Dawson-Hughes B, Heaney RP, Holick MF, Lips P, Meunier PJ, Vieth R. Estimates of optimal vitamin D status. Osteoporos Int 2005;16(7):713-716.

23. Levey AS, Stevens LA, Schmid CH, Zhang YL, Castro AF 3rd, Feldman $\mathrm{HI}$, et al. A new equation to estimate glomerular filtration rate. Ann Intern Med 2009;150(9):604-612.

24. Schwarz U, Amann K, Orth SR, Simonaviciene A, Wessels S, Ritz E. Effect of 1,25 (OH)2 vitamin D3 on glomerulosclerosis in subtotally nephrectomized rats. Kidney Int 1998;53(6):1696-1705.

25. Kim CS, Kim SW. Vitamin D and chronic kidney disease. Korean J Intern Med 2014;29(4):416-427.

26. Deb DK, Sun T, Wong KE, Zhang Z, Ning G, Zhang Y, et al. Combined vitamin $D$ analog and $A T 1$ receptor antagonist synergistically block the development of kidney disease in a model of type 2 diabetes. Kidney Int 2010;77(11):1000-1009.
27. Li YC, Kong J, Wei M, Chen ZF, Liu SQ, Cao LP. 1,25-Dihydroxyvitamin $D(3)$ is a negative endocrine regulator of the renin-angiotensin system. J Clin Invest 2002;110(2):229-238.

28. Zou MS, Yu J, Nie GM, He WS, Luo LM, Xu HT. 1, 25-Dihydroxyvitamin D3 decreases adriamycin-induced podocyte apoptosis and loss. Int J Med Sci 2010;7(5):290-299.

29. Christensen El, Birn H. Megalin and cubilin: synergistic endocytic receptors in renal proximal tubule. Am J Physiol Renal Physiol 2001;280(4):F562-F573.

30. Verhave JC, Hillege HL, Burgerhof JG, Navis G, de Zeeuw D, de Jong $\mathrm{PE}$, et al. Cardiovascular risk factors are differently associated with urinary albumin excretion in men and women. J Am Soc Nephrol 2003;14(5):1330-1335.

31. Rossouw JE, Anderson GL, Prentice RL, LaCroix AZ, Kooperberg C, Stefanick ML, et al. Risks and benefits of estrogen plus progestin in healthy postmenopausal women: principal results from the Women's Health Initiative randomized controlled trial. JAMA 2002;288(3):321-333.

32. Neugarten J, Acharya A, Silbiger SR. Effect of gender on the progression of nondiabetic renal disease: a meta-analysis. $J$ Am Soc Nephrol 2000;11(2):319-329.

33. Quan A, Chakravarty S, Chen JK, Chen JC, Loleh S, Saini N, et al. Androgens augment proximal tubule transport. Am J Physiol Renal Physiol 2004;287(3):F452-F459.

34. Kragt J, van Amerongen B, Killestein J, Dijkstra C, Uitdehaag B, Polman $\mathrm{CH}$, et al. Higher levels of 25-hydroxyvitamin D are associated with a lower incidence of multiple sclerosis only in women. Mult Scler 2009;15(1):9-15.

35. Hagenfeldt Y, Linde K, Sjöberg HE, Zumkeller W, Arver S. Testosterone increases serum 1,25-dihydroxyvitamin $D$ and insulin-like growth factor-l in hypogonadal men. Int J Androl 1992; 15(2):93-102.

36. van Dam RM, Snijder MB, Dekker JM, Stehouwer CD, Bouter $L M$, Heine RJ, et al. Potentially modifiable determinants of vitamin D status in an older population in the Netherlands: the Hoorn Study. Am J Clin Nutr 2007;85(3):755-761.

37. Jacobs DR Jr, Murtaugh MA, Steffes M, Yu X, Roseman J, Goetz FC. Gender- and race-specific determination of albumin excretion rate using albumin-to-creatinine ratio in single, untimed urine specimens: the Coronary Artery Risk Development in Young Adults Study. Am J Epidemiol 2002;155(12):1114-1119. 